\title{
PERCURSOS POÉTICOS: IMAGENS DOS RIOS EM SACIOLOGIA GOIANA
}

\author{
POETIC PATHWAYS: RIVERS' IMAGES IN SACIOLOGIA GOIANA
}

\author{
Damáris de Souza Ramos ${ }^{1}$ \\ Maria Generosa Ferreira Souto ${ }^{2}$
}

\begin{abstract}
RESUMO: Este texto apresenta uma reflexão acerca das imagens dos rios goianos em Saciologia Goiana, de Gilberto Mendonça Teles. Pretende discutir essas imagens como elementos autóctones convertidos em imagens poéticas, capazes de evidenciar a relação do ser com o mundo ao seu redor. Esses sinais nos levam a considerar que o poeta se serviu dos elementos hidrográficos do estado de Goiás para se inspirar. A partir dos poemas, o autor deixa pistas da representação dos rios em sua escrita. Assim, o poeta incorpora o cotidiano e a cultura popular, demonstrando as relações típicas e triviais sobrecarregadas de marcas culturais, afetivas e sociais. Como suporte teórico, dialogaremos com Octávio Paz, Michel de Certeau e Gaston Bachelard. Deste modo, este trabalho perpassará por três vias imbricáveis: lugar, espaço cultural e rios.
\end{abstract}

PALAVRAS-CHAVE: Poesia. Cultura. Cerrado. Águas. Saciologia goiana.

\begin{abstract}
This text presents a reflection about the images of Goiás rivers in Saciologia Goiana, of Gilberto Mendonça Teles. And it aims to discuss these images as autochthonous elements converted into poetic images, able to evidence the relation of the being with the world around him. These signs lead us to consider that the poet has used of the hydrographic elements of the Goiás state for inspiration. From the poems, the author leaves clues of the rivers representation in his writing. Thus, the poet incorporates the daily life and the popular culture, demonstrating the typical and trivial relations overloaded with cultural, emotional and social tags. As theoretical support, we will dialogue with Octávio Paz, Michel de Certeau and Gaston Bachelard. Thereby, this study will thread through for three interwoven ways: place, cultural space and rivers.
\end{abstract}

KEYWORDS: Poetry. Culture. Cerrado. Water. Saciologia goiana.

\footnotetext{
${ }^{1}$ Mestre em Letras - Estudos Literários pela Universidade Estadual de Montes Claros - UNIMONTES. E-mail: damarisouza5@hotmail.com

${ }^{2}$ Doutora em Comunicação e Semiótica pela Pontifícia Universidade Católica de São Paulo. Professor titular efetiva da Universidade Estadual de Montes Claros - UNIMONTES.
} 


\section{Introdução}

As tradições orais asseguram a vitalidade do continuum dos mitos goianos pela poética de Gilberto Mendonça Teles. A memória representada nos poemas de Saciologia Goiana, que trazem a água dos rios para o debate mítico, propõe um voo transverso ao cerrado goiano. Neste voo, o leitor é provocado a adentrar a história do povo goiano e conhecer sua cultura como espelho da memória de um menino-poeta. Para tanto, em alguns poemas, o sujeito poético apresenta um percurso pelos rios goianos, em que expressa parte de suas vivências e costumes tradicionais de seu povo.

Neste percurso, deparamos com signos que transmitem importantes conhecimentos e emoções transmitidos por gerações e gerações. Em "O rio", o eu lírico declara que existe uma trágica história o empurrando para o fundo das nascentes, na direção das cabeceiras do rio Meia-Ponte. Experiência esta, que se presentifica e se materializa nos versos do poema. É possível detectar as passagens do sujeito lírico durante parte de sua vida nos rios. São sinais de lembranças e de intimidades. Daí surgem, além da emoção lírica, aspectos e registros culturais do cerrado goiano e sobre como os rios estabelecem uma ligação afetiva no poeta, sobretudo como o marcou de forma definitiva em sua escrita.

Para demonstrarmos as imagens da cultura popular manifestadas nos hábitos e nos costumes cotidianos em Saciologia Goinana, vamos ler e refletir sobre três poemas. Em "Hidrografia", poema de feição memorialista, o poeta relembra o passado e conta como aconteceram as experiências da vida do menino em muitos rios de Goiás. A discussão se prenderá, também, ao poema “O rio”. Nele, há uma homenagem especial ao rio Meia-Ponte, os versos destacam a importância afetiva do rio. Há um mergulho poético nessas águas, ocorrendo um imbricamento da natureza poeta-e-rio, que se fundem numa experiência quase mística. E ainda, leremos o poema "Ser tão Camões", cujos versos induzem a um emaranhado de imagens, que identificam as marcas do cerrado goiano no sujeito poético, que, apesar dos mergulhos em outras culturas, ainda preserva suas raízes. Além disso, nos ateremos a outros poemas, cuja temática se relaciona aos temas tratados nesta discussão.

Ao organizar a Fortuna Crítica de Saciologia Goiana (2011), Therezinha Mucci Xavier descreve a obra como um verdadeiro testemunho da inteligência lúcida de seu criador, que define a existência, penetra o âmago do ser humano, prova e comprova que tudo é amor. Saciologia Goiana é marcado por uma diversidade de temas e formas, com dois registros: um 
culto e outro popular. Desta forma, compreendemos que uma das entradas de leitura dos poemas é pensar em dois elementos marcantes: a terra natal e a cultura.

Para interpretarmos as imagens dos rios nos poemas investigados apoiaremos esta análise nos pressupostos teóricos sobre as águas de Gaston Bachelard. No que concerne à discussão sobre lugar e espaço cultural, dialogaremos com Michel de Certeau e Néstor García Canclini. Ressaltaremos também, outros estudos críticos sobre a obra poética de Teles.

\section{Do sertão para o mundo: travessias}

Permeado de sombras da terra, o livro Saciologia Goiana, publicado em 1982, por Teles, inaugura um importante momento de concepção estética do autor e acentua fortemente o pacto do poeta com sua terra natal. Nesta análise, procuramos evidenciar como o sujeito lírico constrói campos imagéticos que abrigam a relação do sujeito em seu espaço particular e social. Nos poemas destacados neste trabalho, aparece o sujeito lírico em viagem à terra natal. E nesta viagem contempla os mitos, os costumes, a vida cotidiana e as transformações operadas pelo tempo e pela história tradicional. Os vestígios e reminiscências observados permitem recuperar um universo cheio de imagens carregadas de poesia.

Em Uma Leitura por Goiás: A Sa(o)ciologia de Gilberto Mendonça Teles (2002), a professora Carmelita de Mello Rossi realiza um estudo da obra Saciologia Goiana. Ao delimitar Goiás como espaço de organicidade do trabalho crítico, tem como propósito mostrar como o poeta vê o Estado no cenário caótico da modernidade e, ao mesmo tempo, como utiliza esse espaço para construir um mundo novo. A estudiosa aborda, também, a questão da transmissão da cultura oral e como a introdução dos meios de comunicação de massa constitui-se na atualidade como um fator de ruptura do sistema simbólico, gerando um tipo de violência, que se caracteriza pela perda da memória coletiva e pela submissão à indústria cultural via televisão. $\mathrm{O}$ trabalho também evidencia os mitos que povoam o imaginário goiano, ponto que a autora trata como uma problemática e discute as influências que o poeta recebeu de autores clássicos, especialmente Camões.

Nesse sentido, Saciologia Goiana, de certa forma, tenta recuperar por meio da escrita, muitos elementos culturais que se transformam ao longo do tempo. Segundo Octávio Paz (1996), o poeta consagra sempre uma experiência histórica, que pode ser pessoal, social ou ambas as coisas ao mesmo tempo. Mas ao falar-nos de todos esses sentimentos, experiências e 
pessoas, o poeta nos fala de outra coisa: do que está fazendo, do que está sendo diante de nós e em nós. E ainda conforme Paz, o poema, como toda criação humana, é um produto histórico, filho de um tempo e de um lugar; mas é algo que transcende o histórico e se situa em um tempo anterior a toda história, no princípio do princípio.

Ao reportarmos aos poemas escolhidos para esta reflexão, podemos acrescentar ao pensamento de Paz, a questão da cultura como força motriz criadora, pois o poema não teria sentido sem a comunidade que o alimenta e à qual alimenta. A escrita de Teles se insere entre aquelas que se dedicam à busca constante pela experimentação e transfiguração da palavra em poesia, uma vez que sua poesia é uma travessia cujo artista experimenta a própria linguagem e não teme em arriscar-se. Nesse sentido, observamos nos poemas a presença marcante de elementos telúricos e da cultura popular. São particularidades cotidianas que só poderiam ser preservadas, na forma poética, por um sujeito que as experimentara. O escritor goiano entrelaça em seus versos temas populares e clássicos, o trivial e o sofisticado, o campo e a cidade.

Para Néstor García Canclini (2008), a cultura popular na modernidade se desenvolveu transformando-se. E é na literatura que podemos observar tal fenômeno, pois a Literatura abrange diversas mesclas interculturais, não só estéticas, mas também temáticas. E é desta maneira que o sujeito lírico transmite nos versos os cenários sociais da vida comum, os costumes alimentares, as festas típicas e os muitos significados que integram a cultura popular, tornando-se porta de entrada para o entendimento das tradições que se circunscrevem na modernidade.

E a despeito das transformações culturais, o poeta é o guardião de um tempo ou de um lugar capaz de ser recuperado pela escrita. Dessa forma, nasce a poesia que "alude a um passado que não é datável, mas a rigor nem sequer é passado: é uma categoria temporal que flutua, por assim dizer, sobre o tempo, sempre com avidez de presente" (PAZ, 1996. p. 53). Vejamos, pois, o poema "Hidrografia":

\footnotetext{
Os rios de Goiás, além de rios de verdade, tem peixes, bichos, lendas. Tem várzeas e vãos e seus resfrios no fundo dos gerais e das fazendas.

Neles me batizei, lavei meu couro, Aprendi a nadar e, bem menino, Fui-me encontrando neles, no tesouro que imaginava haver no meu destino.
} 
(TELES, 2004, p. 44)

A questão do tempo já transcorrido importa-nos, sobretudo, quando tratamos de memória, pois é através da recordação, da capacidade de reconstituir pela escrita no momento presente, que depreendemos um tempo vivido ou imaginado. A referência a acontecimentos como este, banais, deixam marcados na memória aquele instante de interesse especial. Para que possamos compreender melhor o modo pelo qual um autor memorialista consegue emergir de um tempo distante recordações, precisamos retornar à ideia da presença-ausência pensada por Paz, pois segundo ele:

ao inverso do que ocorrem como os axiomas dos matemáticos, as verdades dos físicos ou as ideias dos filósofos, o poema não abstrai a experiência: esse tempo está vivo, é um instante pleno de toda sua particularidade irredutível e é perpetuamente suscetível de repetir-se um outro instante, de reengendrar-se e iluminar com sua luz novos instantes, novas experiências (PAZ, 1996, p. 53).

Como se vê, Paz alude ao texto memorialista e à possibilidade de se emergir em tempos distantes, passados, reminiscentes. E para bem ilustrar a citação, é válido trazermos as lembranças da experiência do banho de rio de um tempo-menino com seus segredos e mistérios transitórios, como a água, que Gaston Bachelard (1998) afirma ser "o elemento transitório".

Desse modo, a experiência do banho de rio ainda se mantém na memória do menino, e assim continua no imaginário vivo e atemporal. Além disso, podemos perceber um pressentimento, uma destinação. O sujeito lírico pressente que as águas dos rios goianos mantêm segredos e mistérios, pois são águas supremas, "convertidas em heroína da doçura e da pureza", segundo Bachelard. E essa sensação aparece ao longo do poema, pois ao contemplar essa lembrança, o sujeito lírico contempla também uma emoção anterior, àquela que pressentira o tesouro que havia em seu destino. Como podemos constatar em outros versos do poema:

No Meia-Ponte, armei os infinitos da minha vida e andei sobre a corrente, pronunciando a tônica dos mitos espalhados nas margens pela enchente. (TELES, 2004, p. 44)

É como se aquelas águas revelassem outros signos e outras significações, além da simples lembrança de menino. Bachelard ainda ressalta que "se dermos seu justo lugar à 
imaginação material nas cosmogonias imaginárias, compreenderemos que a água doce é a verdadeira água mítica" (BACHELARD, 1998. p. 158). E assim, apreendemos que as águas doces dos rios goianos se fazem mitos que teimam em continuarem vivos.

Tal experiência nos remete a outros hipertextos de invocação da infância, de caráter memorialístico. É o caso do livro Boitempo, de Carlos Drummond de Andrade, um texto sobrecarregado de memórias do coração. Nesse livro podemos reencontrar o menino antigo que revive e presentifica sua experiência, eterniza e eleva o simples cotidiano à notação lírica. São momentos despretensiosos, singelos, como podemos constatar nos versos de "Hora Mágica":

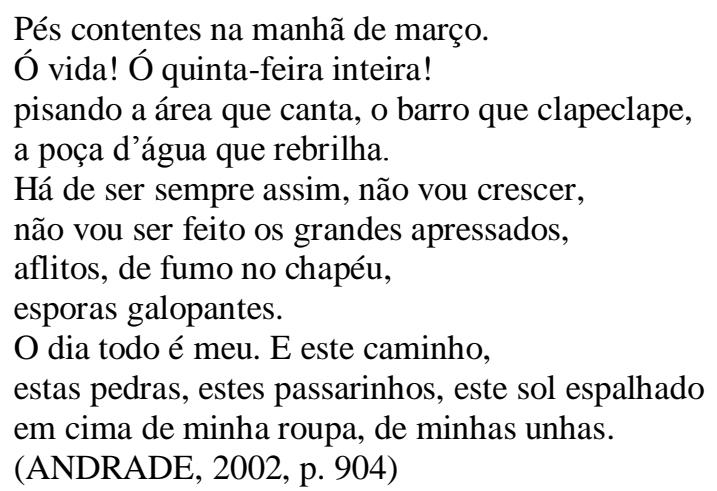

Mas nem só de momentos líricos e felizes é feita a recordação, e nem sempre a recordação é feita de fatos íntimos. Muitas vezes a memória registra e prolonga uma lembrança coletiva. No caso de "Hora Mágica" de Drummond, e de "O rio" de Teles há um elemento comum: o desejo de prolongar o instante mágico. Desta maneira, podemos constatar que esse recurso é recorrente em ambos os poetas, o mineiro e o goiano.

No que se refere aos poemas do livro Saciologia Goiana, percebemos que a emoção do sujeito lírico aponta para duas direções, pois ao recordar esses fatos da vida comum, sugere ao leitor uma conexão particular e sentimental, mas também estabelece uma valoração das trivialidades e costumes locais, numa dimensão que sai do plano da simples emoção íntima e estabelece uma comunicação comungada em emoção coletiva. Essa rememoração assume um aspecto de relato, de um novo mito construído do vasto tecido do imaginário popular; construído desses rios e da experiência da tradição. Para Michel de Certeau, os relatos cotidianos são como transportes coletivos. No dizer dele,

(...) na Atenas contemporânea, os transportes coletivos se chamam metaphorai. Para ir para o trabalho ou voltar para casa, toma-se uma "metáfora" - um ônibus ou um trem. Os relatos poderiam igualmente ter esse nome: todos os dias eles atravessam e 
organizam lugares; eles o selecionam e os reúnem num só conjunto; deles fazem frases e itinerários (CERTEAU, 1994, P. 199).

Assim ocorre também com a memória, uma espécie de metaphorai, um meio de transporte que abriga relatos e emoções. E desta maneira o sujeito lírico no poema "Hidrografia" menciona vários rios goianos e como cada um deles o marcou de forma particular. No rio Meia-Ponte, há um encontro com o mistério e com o infinito; No Grimpas, o sujeito lírico faz referência à febre que certamente foi provocada pelo mercúrio, elemento utilizado pelo garimpo. Cada rio é uma presença diferente, representa uma experiência vivida ora pelo menino, ora pelo poeta. O poema ainda presta homenagem aos rios Turvo, Corumbá, Paranaíba, Tocantins, Araguaia, dentre outros rios importantes do estado de Goiás.

O poema rememora as imagens dos rios. Além disso, apresenta um percurso imaginário e convida ao leitor a mergulhar nessas águas. Em outra estrofe do poema "Hidrografia" encontramos outras passagens que evidenciam as marcas afetivas dos rios operadas pela linguagem e que, certamente, se presentificam na memória do sujeito lírico. Vejamos:

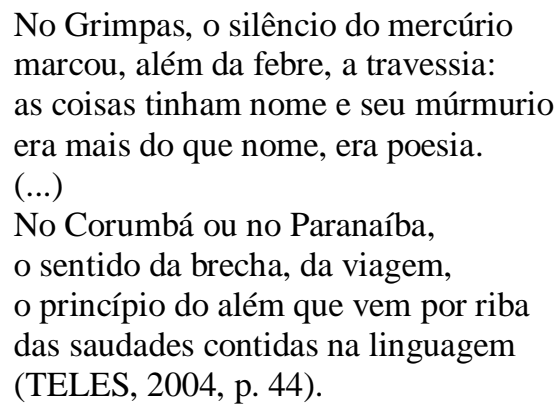

O sujeito lírico procede numa espécie de reconstituição de cenas do passado quando aproxima o passado do presente, e, ao mesmo tempo, institui um ritual que presentifica as sensações. Nessa viagem sentimental, depreendemos que as impressões do sujeito lírico desembocam nas afirmações de Gaston Bachelard, quando diz que, na substância da água, há um tipo de intimidade, intimidade bem diferente das que as "profundezas" do fogo ou da pedra sugerem. Nas águas dos rios goianos observamos um sujeito lírico numa viagem imaginária e que ao mesmo tempo transporta para a poesia sinais e germes que vêm do fundo de sua cultura. A despeito da amplitude que o signo da água evoca na concepção de Bachelard, o autor assinala que: 
A cultura transmite-nos formas - com demasiada frequência palavras. Se soubéssemos reencontrar apesar da cultura, um pouco de devaneio natural, um pouco de devaneio diante da natureza, compreenderíamos que o simbolismo é um poder material. Nosso devaneio pessoal restabeleceria com toda naturalidade os símbolos atávicos, porque os símbolos atávicos são símbolos naturais.

(BACHELARD, 1998, p. 141)

É dessa maneira que o sonhador, o poeta, poetiza as coisas, dá-lhe uma segunda natureza. Pois apesar da cultura, o poema transcende a esse referencial e traz para as palavras a emoção do devaneio. E esse símbolo atávico ou essa marca cultural que identifica o sujeito à sua origem e ao seu lugar, está expresso nos versos do poema "Ser tão Camões". Vejamos:

\author{
Um rio se levanta da planície \\ Goiana e se detém calamitoso \\ para lutar comigo e revelar-me \\ o mistério mais fundo do sertão. \\ (TELES, 2004, p. 36)
}

$\mathrm{Na}$ estrofe observamos que o sujeito lírico começa um diálogo com o rio. Ao longo do poema, é o rio quem revela ao sujeito lírico o mistério e os segredos de sua predestinação. Pois para manter-se vivo e produtivo o discurso do rio é categórico:

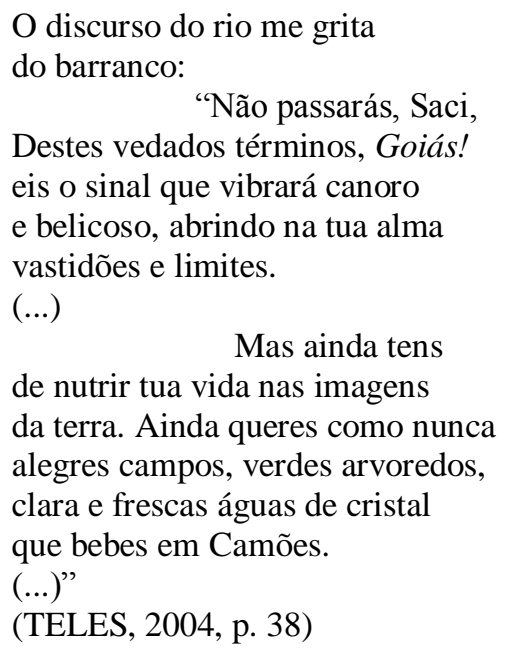

O poema aponta em muitas direções, a mais acentuada é como o lugar marca definitivamente o sujeito lírico. E essa dependência afetiva está expressa na ideia de que é necessário nutrir-se das imagens da terra, ou seja, recorrer sempre a esse começo e a essa 
fonte para revigorar-se. Ao mesmo tempo o poema remete à busca do tempo perdido, ou à lei do eterno retorno.

Ainda podemos inferir uma questão imbricada, isto é, a relação espacial que o rio representa. Michel de Certeau afirma que o espaço é um lugar praticado, neste caso, o rio é um lugar imóvel que ao mesmo tempo se transforma em espaço a partir de uma associação de um relato, de uma história ou de um poema. O espaço é o temp(l)o da poesia e o rio um lugar de passagem. Lugar é imóvel e o espaço é um percurso. Essa noção de espacialidade sugere uma localização da subjetividade. As imagens que o lugar provoca em nossa memória são a matéria (os relatos) do lugar e o espaço é personalíssimo, e ao mesmo tempo ambíguo. Segundo Certeau:

\begin{abstract}
O espaço estaria para o lugar como a palavra falada, isto é, quando é percebida na ambiguidade de uma efetuação, mudada em um termo que depende de múltiplas convenções, colocada como o ato de um presente (ou de um tempo), e modificado pelas transformações devidas a proximidades sucessivas. Diversamente de lugar, não tem, portanto a univocidade nem a estabilidade de um "próprio".

(CERTEAU, 1994, p. 202)
\end{abstract}

Pois, ainda conforme Certeau, os relatos efetuam, portanto, um trabalho que, incessantemente, transforma lugares em espaços ou espaços em lugares. Para ele, onde os relatos desaparecem, existe perda de espaço como se constata ora na cidade ora na região rural. Por isso os relatos cotidianos e orais são operações e bricolagens capazes de formar mitos, e possuem a função de fundar e articular espaços. Compreendemos então, que os poemas discutidos nesse trabalho apontam para uma reflexão semelhante. O poeta em seus versos pratica uma espécie de relato. É, portanto um relato fragmentado, carregado de ambiguidades, uma operação subjetiva e pessoal. Para Certeau, o rio como as árvores e a ponte tem um papel mediador, e são lugares de fronteira, lugares de passagem.

Em Saciologia Goiana, as imagens observadas dos rios, possuem de certa forma, um caráter transitório e de passagem. Ocorre, neste sentido, o imbricamento do rio com o homem, de forma memorialística, traduzindo lugar e espaço como um cabedal de cultura tradicional, que perpassa gerações, conhecimentos, sabedorias, reminiscências. Essa sobreposição de imagens aparece na forma do rio como lugar móvel que se transforma em espaço fluido, como nos versos finais do poema "Ser tão Camões", em que o rio encerra o discurso, "todo o teu ser/tão cheio de lirismo e de epopéias/tenta escapar-se em vão aos refrigérios/dos fundões de Goiás". Além do imbricamento do rio-homem-lugar-espaço cultural, os versos sugerem um 
fatalismo, pois toda viagem é uma viagem de volta para a terra natal. E nesse caso, a viagem de volta é feita pela escrita.

É uma recorrência poética, assim como Drummond recupera Itabira em seus poemas, o poeta goiano recupera e recria Goiás, ao afirmar que "só te vejo, Goiás, quando me afasto", ou seja, "de perto, as coisas vivem pelo ofício/do cotidiano" e "de longe, não, nem tudo está perdido". É, portanto uma travessia, pois ao viajar por outros rios e outros lugares, o poeta não se desgarra de sua origem, e é pela escrita que estes sinais permanecem guardados, continuamente.

\section{Da poesia para o sertão: reencontro}

Em Teoria da Viagem, Michel Onfray apresenta a viagem numa dimensão de subjetividade, pois antes da partida para lugares distantes, toda viagem começa a partir de um desejo, de uma escolha. Em Saciologia Goiana observam-se muitos poemas em que o sujeito lírico está em movimento. Um movimento sempre em direção ao começo, ao retorno. O leitor é convidado a contemplar as imagens recuperadas pela memória afetiva, quais sejam: os mitos, as lendas, o cotidiano e os rios. E, é desta maneira que a poesia transporta as imagens de um lugar ou de um espaço para a dimensão do simbólico, pois deparamos com um Goiás reinventado a partir do poema. Na qual podemos dizer que essa tendência em sacralizar a terra amada, é constante em todo o livro. Desse modo, o poeta canta a beleza de sua terra e de sua gente. Apresenta ao leitor uma terra em que tudo se converte em imaginário.

Nessa perspectiva é que se diz que o poeta abre caminhos para os mundos paralelos, invisíveis, insuspeitados, o mundo do imaginário. Ainda pela magia das palavras e pela força integradora da palavra poética, o poeta cria a ilusão da presença de uma ausência, tornando suportável a realidade. Mas a poesia não trata apenas do mundo do imaginário, é preciso supor que a arte mantém seu lugar de cultura e seus criadores em vão tentam escapar a essa realidade. Aspecto este, perceptível no poema, que podemos observar como sujeito lírico assume sua condição de estar ligado à sua origem. Vejamos nesses outros versos do poema "Ser tão Camões":

Terás sempre

o sal da terra e a luminosa sombra que te guia e divide, e te faz duplo, real e transparente, mas concreto nas tuas peripécias 
(TELES, 2004, p. 37).

Os versos sugerem, a partir do título, que o sujeito lírico mantém sua duplicidade de ser e estar no mundo. Nem tanto Camões e nem tanto sertão. Nicolás Extremera Tapia, em um texto intitulado "Un calambur regionalista de Gilberto Mendonça Teles" faz uma leitura detalhada do poema "Ser tão Camões" e destaca vários elementos da proximidade que o poeta goiano tem com o poeta português. Além das alusões às obras de Camões, especialmente aos cantos de "Os lusíadas", Tapia destaca o simbolismo, o regionalismo e o processo de comparación-transferencia-fusión-inversión que constitui a composição do poema, segundo ele:

\begin{abstract}
Estos símbolos regionalistas por su propia naturaleza están limitados a accidentes o peculiaridades geográfico-climáticos (rio, sertão, fundões), a las flora y fauna (botos, iaras) de la región o a la geología (pepita de ouro, veio); otros: Saci, leyendas tradicionales, surgen de la antropología y el folklore regionales. En "Ser tão Camões" convergen ambos caudales simbólicos: el camoniano y el regionalista y el poema se articula como una réplica, un contrapunto, un diálogo con su homólogo portugués de outro siglo, de otro continente, de otro país, de otra región.
\end{abstract}

(TAPIA, 2011, p. 75)

Depreendemos, então, que essa limitação geográfica constitui um importante elemento de compreensão deste livro. E a despeito disso, não podemos ignorar que a cultura e os fatos pessoais se imbricam na composição da escrita. Nesse caso, as experiências cotidianas, a cultura popular, adquirem maior relevo neste livro, intencionalmente composto como uma epopeia da terra amada. Ainda conforme Tapia, o regionalismo em Teles comporta um desejo integrador da população local, pois sua saciologia está fundada em partilhar o espaço geográfico e também sua história. Não se trata, contudo, em reduzir a capacidade artística do poeta a suas referências, sejam elas culturais ou pessoais. Nesse sentido, é necessário nos reportar a Antonio Candido que em sua obra Formação da literatura Brasileira (Momentos decisivos), 1981, onde o crítico reconhece que as impressões de cada sujeito constituem matéria-prima para seu ato criador, pois segundo ele:

Uma obra é uma realidade autônoma, cujo valor está na fórmula que obteve para plasmar elementos não-literários: impressões, paixões, ideias, fatos, acontecimentos, que são a matéria-prima do ato criador. A sua importância quase nunca é devida à circunstância de exprimir um aspecto da realidade, social ou individual, mas à maneira por que o faz. No limite, o elemento decisivo é o que permite compreendêla e apreciá-la, mesmo que não soubéssemos onde, quando, por quem foi escrita.

(CANDIDO, 1981, p. 33) 
É, portanto, da capacidade do autor em plasmar esses elementos e transformá-los em uma obra artística que podemos perceber sua genialidade. Teles privilegia a simplicidade em sua escrita, sem, contudo ser trivial. Com elevado grau de sofisticação na construção de seus poemas, constatado pelo uso da técnica, metáforas, neologismos e simbolismos diversos, tais estratégias evocam emanações no leitor, uma vez que esse não seria indiferente à leitura de seus versos. No poema "O rio", é possível constatar muitas das assertivas de Candido, vejamos:

\author{
A história desse rio é a minha estória: \\ o negro-d'àgua, o sucuri, o pé-de-pato, \\ a cobra, a febre, os peixes, as urtigas \\ e a tranqüila nudez da mulher que veio de Anápolis \\ para servir os homens na festa de São João. \\ $\mathrm{Na}$ antiga cidade de Meia-Ponte \\ o rio se chama das Almas e corre para o Norte, \\ mas em Inhumas, Brazabrantes e Bela Vista \\ as almas é que se banham de noitinha no Meia-Ponte, \\ assustando os meninos que tomam banho escondido. \\ (TELES, 2004, p. 46-47)
}

Nessas estrofes podemos contemplar uma estória de uma vida e sentir que essas conexões podem ser facilmente partilhadas. Os versos estabelecem alto poder comunicativo com o leitor ao partir de um lugar comum. Observa-se um jogo íntimo nos versos, reforçado pelo uso do pronome "minha", tal recurso confere ao poema um caráter de diário pessoal compartilhado pelos leitores. Considerando ainda a importância da cultura popular e suas diversas manifestações na vida cotidiana, o poema "Manifesto da cozinha goiana" apresenta um cardápio local e possibilita visualizar parte dos hábitos alimentares e as comidas típicas de Goiás. Atentemo-nos aos seguintes versos:

Na cozinha goiana a fartura tem níveis e dias de festa. das águas e das secas.

Há coisas que variam no ritmo E coisas reservadas nesse espaço indeciso entre roça e cidade.

Apesar das influências que vêm de todo lado, apesar dos pesares e dos goianos sem forma e tradição,

nós sabemos muito bem que a essência da comida goiana não se altera e parece que sempre se manterá à prova do discurso do arroz com guabiroba. (TELES, 2004, p. 95) 
Nos versos acima, o sujeito lírico tem consciência do código de valores e da tradição alimentar a que sua gente está submetida. É importante sublinhar a resistência de um povo, para preservação de sua cultura e de muitos hábitos que sobrevivem apesar das influências que vêm de todo lado. E uma das vias de acesso a esses poemas aqui discutidos é não pensálos de modo unilateral. E o leitor sensível pressente que cada face, seja ela de ordem social ou pessoal, se for suprimida, compromete a unicidade que o poema integra.

Cada lugar escolhe, por diversas razões, tanto climáticas quanto culturais suas preferências alimentares. O cultivo das plantas, a agricultura em geral, exerce influência sobre a vida, os costumes e a culinária de um povo. Michel de Certeau acrescenta que os alimentos se ordenam em cada região, segundo um código detalhado de valores, de regras e de símbolos, em torno do qual se organiza o modelo alimentar de uma área cultural num determinado período, segundo ele "é nessa fonte, neste código detalhado, mais ou menos bem conhecido, que a cozinheira vai haurir sua inspiração, suas possibilidades de compra e de preparação, seu humor e os desejos de seus convivas" (CERTEAU, 1994, p. 233). Nesse sentido, pela capacidade integradora da palavra poética, o sujeito lírico define um percurso em direção à terra natal, sempre em direção ao começo. E tal circunstância remete à experiência de um conhecimento das coisas e de uma possibilidade de comunhão. São sinais que repercutem na reflexão do leitor a partir das confidências do poeta. Pois a poesia rompe com o modo convencional de perceber e julgar as coisas, e instaura certa ingenuidade do olhar, àquela que faz como se tudo fosse visto pela primeira vez.

\section{Considerações finais}

No sentido que atribuímos à relação das imagens da cultura e suas manifestações na vida cotidiana nos poemas investigados, constitui-se um sistema de imagens entrelaçadas, que não estão isoladas, mas diretamente ligadas à vida. $\mathrm{O}$ poeta se ocupa em registrar as situações humanas e as vivências. E estimula novos olhares sobre as pequenas estórias que constituem a vida. Essas descrições estabelecem diálogos entre o ser e o mundo ao seu redor. E, estes diálogos, são chaves para discussões literárias sobre os processos de reconstituição dos valores humanos por meio da escrita. Além disso, constatamos as marcas que a vida imprime no ser, e como elas definem de modo particular, a relação de cada um diante de suas memórias. 
E esses dados efetuam, portanto, um procedimento esclarecido por Certeau, que a vida comum é um microcosmo cheio de imagens, símbolos, arte e leis. Sendo assim, é nesse microcosmo, apesar das tradições, linguagens e símbolos, que as pessoas individualizam e alteram a cultura de massa, os objetos utilitários, os rituais, as leis e a linguagem, de forma a apropriá-los. Cada pessoa confere relevância às suas experiências sejam elas sociais ou pessoais. E por ter marcado caminho e por ter sido marcado, o sujeito lírico nos revela: "para não me perder, em cada margem/pus tudo o que era meu e que era amado,/mesmo que fosse apenas uma imagem/uma figura obscura do passado". E, nos versos do poema intitulado "Sinais", nos diz que "há medo de ida e volta na passagem" o melhor mesmo "é refugiar-me na linguagem.” Pois a melhor maneira de permanecer vivo, na história e na memória é por meio da escrita.

Nota

\footnotetext{
${ }^{i}$ Estes símbolos regionalistas por sua natureza são limitados a acidentes e peculiaridades geográfico-climáticas (rio, sertão, fundões), a flora e fauna (botos, iaras) da região ou da geologia (pepita de ouro, veio) outro: Saci, lendas tradicionais, emergindo da antropologia e do folclore regional. Em "Ser tão Camões" ambos os fluxos simbólicos convergem: o camoniano e regionalista e o poema está estruturado como uma réplica, um contraponto, um diálogo com o seu homólogo português de outro século, de outro continente, de outro país, de outra região. (tradução nossa).
}

\section{Referências}

ANDRADE, Carlos Drummond de. Poesia completa. Rio de Janeiro: Nova Aguilar, 2002.

BACHELARD, Gaston. A água e os sonhos. São Paulo: Martins Fontes, 1998.

CANCLINI, Néstor García. Culturas híbridas: Estratégias para Entrar e Sair da Modernidade/Néstor García Canclini; tradução Heloísa Pezza Cintrão, Ana Regina Lessa; tradução da introdução Gênese Andrade. - 4. Ed. São Paulo: Edusp, 2008.

CANDIDO, Antonio. Formação da literatura brasileira/Momentos decisivos. $7^{a}$ Ed. Belo Horizonte: Editora Itatiaia Limitada, 1981.

CERTEAU, Michel de. A invenção do cotidiano: 1.artes de fazer/Michel de Certeau; tradução de Ephraim Ferreira Alves. Petrópolis, RJ: Vozes, 1994. 
ONFRAY, Michel. Teoria da viagem. Porto Alegre: L \& PM Editores, 2009.

PAZ, Octávio. Signos em rotação. São Paulo: Perspectiva, 1996.

ROSSI, Carmelita de Mello. Uma Leitura por Goiás: A Sa (o) ciologia de Gilberto Mendonça Teles. Universidade Federal de Goiás, 2002. Dissertação de Mestrado.

TELES, Gilberto Mendonça. Saciologia goiana. Goiâna: Kelps, 2004.

TAPIA, Nicolás Extremera. Un calambur regionalista de Gilberto Mendonça Teles. In: XAVIER, Terezinha Mucci. Fortuna Crítica de Saciologia goiana. Rio de Janeiro: Edições Galo Branco, 2011. 